\title{
A Comparison Of Mission Statements Of National Blue Ribbon Schools And Unacceptable Texas High Schools
}

John Charles Perfetto, Weslaco High School, USA

Glenda Holland, Texas A\&M University - Commerce, USA

Rebecca Davis, Texas A\&M University - Kingsville, USA

La Vonne Fedynich, Texas A\&M University - Kingsville, USA

\begin{abstract}
This study was conducted to determine the themes present in the context of high schools, to determine any significant differences in themes for high and low performing high schools, and to determine if significant differences were present for the same sample of high schools based on school size. An analysis of the content of mission statements identified 31 dominant themes: Students, Providing, All, Community, Learning, Academics, Developing, Responsible, Education, Environment, Preparing, Productive, Success, Lifelong Learning, Individual, Citizen, Excellence, Skills, Society, Committed, Promotes, Achievement, Diversity, Knowledge, Nature, Challenge, Future, Partnership, Quality, Potential, and Safe. Significant differences were found between the group of high and low performing high schools for the themes of Academics, Excellence, Challenge, Learning, Nurture, and Lifelong Learning $(p \leq .05)$. Analysis of mission statements grouped by size yielded a significant difference for the theme of Knowledge for large size high schools as compared to small and medium size high schools.
\end{abstract}

Keywords: Mission Statements; High Schools; Achievement

\section{INTRODUCTION}

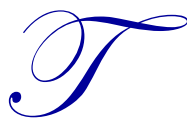

he writing of mission statements is a complex task. Ireland and Hitt (1992) wrote, "Developing mission statements requires diligence, tolerance of ambiguous conditions and inputs, and the devotion of considerable amounts of time" (p. 38). Controversies sometimes arise during the development of a mission statement (Ireland \& Hitt, 1992). High school leaders who formulate mission statements need to know how to deal with controversies and decide what qualities that they want their students to exhibit. The controversies in writing mission statements create a differential effect on themes present in the context of mission statements.

"Creating mission statements that commit an organization to specific ends can be a scary task" (Carver, 2000 , p. 22). Abelman and Dalessandro (2008) found that $80 \%$ of colleges had to reformulate their mission statements to keep pace with the changing demands in which colleges operated. The changing demands in society also created a need for high schools to change and rethink their mission statements so that these institutions would be able to prepare students for entry into college, vocational schools, or other additional higher-learning institutions. To keep pace with these changing demands of society, Ayers (2002b) found that administrators in community colleges tended to take a lead in developing these statements. Levin (2000) wrote that organizational culture, fiscal resources, and organizational identity were three items that needed to be revisited regularly in regard to mission statements. Ireland and Hitt (1992) wrote that mission statements provide "motivation and general direction" (p. 35) for an organization.

A review of literature revealed that the writing of mission statements is an integral part of what institutions focus upon and what they stand for. The context of the language contained in mission statements is influenced by 
the skills and differences of the individuals who reside within each campus. In addition, according to Davies (1986), research on mission statements was limited because prior researchers did not examine the "the presuppositions upon which they are grounded" (p. 85). Research from this study contributed to the current body of research on mission statements, specifically in high schools.

A very limited percentage of high schools in the United States performed at a high level based on the accountability standards arising out of the NCLB Act of 2001, while other high schools performed at an exceedingly low level of performance (United States Department of Education, 2008). Educators across the nation have researched factors that correspond to an increase in the performance of an institution. To accentuate the feeling of urgency that existed in United States to reform high schools, Raynor (2007) wrote, "We are currently immersed in a national movement to reform high schools that is unprecedented in the history of secondary public education" ( $p$. $51)$.

Mission statements continue to be studied for their merit and value to the organization in which they are written to serve. Administrators and other personnel who write mission statements for their schools may write better mission statements if they are aware of the themes that link directly to high recurring performance of a high school. The purpose of the current study was to identify the themes that were present in the context of mission statements of high schools and to determine the most frequently occurring themes present in the mission statements of low as well as high performing high schools. In addition, the same sample of high schools was used to determine differences in the occurrences of themes for small, medium, and large size high schools.

\section{METHOD}

This study included a mixed-methods analysis of mission statements collected from USDE Blue Ribbon high schools and TEA (Texas Education Agency) unacceptable high schools. Both qualitative and quantitative methods were used to identify and analyze themes among the group of high and low performing high schools as well as for small, medium, and large size high schools. The quantitative design was descriptive in nature. Quantitative data were used to determine qualitative themes, which were analyzed using quantitative methods. This was only possible after all data had been coded and quantitized (Tashakkori \& Teddlie, 1998). Quantizing of data allowed qualitative themes to be identified from which quantitative methods could be used to analyze this data. Examples of each identified theme that were found in the study and which originated from a USDE Blue Ribbon high school were provided to assist the reader in understanding how each theme was used in the context of mission statements examined and to provide exemplar phrases for each identified theme.

The study also included a causal-comparative design in that differences among missions statement themes from a group of high performing high schools based upon state accountability were compared to the themes identified for low performing high schools based upon accountability. The same sample of high schools was categorized into groups of small, medium, and large size high schools and comparisons were made on the differences in themes attributed to the size of the school. Quantitative methods of analysis were used as techniques to generate frequency distributions, display data, and to determine statistically significant relationships. The Pearson chi-square analysis was used to determine statistical differences among the previously identified groups.

\section{Population and Sample}

The sample used to represent the group of high performing high schools for this study comprised of 1) the 49 public USDE Blue Ribbon high schools that served grades 9-12 and were not designated as a specific magnet school or part of a college program for the 2008 school year and 2) 50 of 57 high schools identified by the Texas Education Agency that were designated as unacceptable for the same school year for high schools that served grades 9-12. All data gathered in the study originated from openly accessible non-secure databases maintained by the Texas Education Agency, the University Interscholastic League, the United States Department of Education, and official high school or district websites, or emailed from a school representative via internet. 


\section{Data Analysis}

The method of constant comparison (Glaser \& Strauss, 1967) was used to identify similar meaning words and/or phrases that were present in the mission statements of high schools in the sample. After reading each mission statement and coding all words/phrases, the frequency in which each theme occurred was determined. The frequency of each theme was converted to a percentage. Percentages in which each theme occurred were used as prevalence rates. Prevalence rates served as effect size measures (Owuegbuzie, 2000). A decision was made that a theme was present when it occurred a minimum of 11 times. The cut-off point of 11 was used because it represented a prevalence rate of $12 \%$, which translated to a small to medium effect size using Cohen's 1988 criteria (Cohen, 1988).

Next, the frequencies in which each identified theme occurred were displayed from greatest to least, respectively. Percentages were calculated for the occurrence of themes for the group of high and low performing high schools. Percentages were also calculated for the occurrence of themes for the group of small, medium, and large size high schools. A Pearson chi-square analysis was performed to determine significant differences among themes for the group of high and low performing high schools and for the group of small, medium, and large size high schools. An alpha level of 5\% was established as the significance level for the Pearson chi-square analysis (Green \& Salkind, 2005).

\section{RESULTS}

The results section is divided into three sections - dominant themes, school labels, and school size.

\section{Dominant Themes}

Thirty-one dominant themes were identified. The themes, along with each theme's frequency from greatest to least were: Students (62), Providing (32), All (30), Community (28), Learning (28), Academics (27), Developing (27), Responsibility (26), Education (25), Environment (25), Preparing (25), Productive (24), Success (23), Lifelong Learning (23), Individual (21), Citizen (20), Excellence (20), Skills (20), Society (18), Committed (17), Promotes (17), Achievement (16), Diversity (14), Knowledge (14), Nurture (14), Challenge (13), Future (13), Partnership (13), Quality (12), Potential (12), and Safe (12).

\section{School Label}

Pearson chi-square analysis for differences between labels (USDE Blued Ribbon high schools and TEA unacceptable high schools) yielded differences for the themes of Excellence, Academics, Learning, Challenge, Nurture, and Lifelong Learning. P-values and Cramer's V for the Pearson chi-square analysis are displayed next.

For Excellence $(p=.002), 32.7 \%$ of USDE Blue Ribbon high schools had "Excellence" present in mission statements compared to $8.0 \%$ for TEA unacceptable high schools. Based upon Cramer's V of .31, the effect size was determined to be moderate in nature (Cohen, 1988).

For Academics ( $p=.003$ ), $40.8 \%$ of USDE Blue Ribbon high schools had "Academics" present in mission statements compared to $8.0 \%$ for TEA unacceptable high schools. Based upon Cramer's V of .30, the effect size was determined to be moderate in nature.

For Learning ( $p=.006$ ), 40.8\% of USDE Blue Ribbon high schools had "Learning" in mission statements compared to $16.0 \%$ for TEA unacceptable high schools. Based upon Cramer's V of .28, the effect size was determined to be moderate in nature.

For Challenge ( $p=.007), 22.4 \%$ of USDE Blue Ribbon high schools had "Challenge" in mission statements compared to $4.0 \%$ for TEA Unacceptable high schools. Based upon Cramer's V of .21, the effect size was determined to be moderate in nature. 
For Nurture $(p=.02), 22.4 \%$ of USDE Blue Ribbon high school having "Nurture" in mission statements compared to $6.0 \%$ for TEA Unacceptable high schools. Based upon Cramer's V of .24, the effect size was determined to be moderate in nature.

For Lifelong Learning $(p=.03)$, 32.7\% of USDE Blue Ribbon high school had "Lifelong Learning" in mission statements compared to $14.0 \%$ for TEA unacceptable high schools. Based upon Cramer's V of .21, the effect size was determined to be moderate in nature.

\section{School Size}

A Pearson chi-square analysis yielded one significant difference between small, medium, and large size high schools for the theme of Knowledge: Knowledge $(p=.03)$, Cramer's $V=.26$, with $24.2 \%$ of large size high schools having this theme in the context of mission statements compared to $14.8 \%$ for medium size high schools, and $0 \%$ of small size high schools having this theme present. Based upon Cramer's V of .26, the effect size was determined to be moderate in nature (Cohen, 1988).

\section{DISCUSSION}

Themes identified in this study were related to previous research in the a few ways. Morphew and Hartley (2006), from 300 randomly selected four-year United States colleges and universities, were in agreement with the following themes in this study: Developing, Preparing, and Community. A mission statement study comparing twoyear colleges and vocational institutions to four-year colleges and universities was conducted by Wang et al. (2007). Similarities to four-year colleges and universities were found for the themes of Academics, Citizens, and Diversity. Similarities to two-year colleges and vocational institutions were found for the themes Skills and Developing.

Bradley and Taylor (1998) indicated a change of performance for students in secondary schools that had a student population of more than 1,200. This study was in agreement with the theme of Knowledge. The theme of Knowledge differed significantly for a high school with more than 1,200 students compared to that of either small or medium size high schools.

Fairchild (1984), in which a generalization was made that small schools may perform better due to the greater attention teachers give students, was not supported by this study. Themes for small size high schools in this study did not differ significantly from those of either medium or large size high schools. Lastly, a study conducted by Barnett, Glass, Snowdon, and Stringer (2002), which indicated a significant difference in performance for large size high schools, was in agreement with the theme of Knowledge for this study. The theme of Knowledge differed significantly from that of small or medium size high schools. Results of this study support prior studies showing that larger high schools emphasize acquisition of knowledge at a significantly higher level.

\section{CONCLUSIONS}

For the most part, themes identified for high schools in this study differed from those found in previous research for colleges and universities. The research in this study added to the previous research conducted by Boerema (2006) for high schools in Canada. High performing schools differed from low performing high schools for the themes of Academics, Student learning, Challenging students, Providing a nurturing/caring environment for learning, Expecting excellence in what students were learning, and Emphasizing that learning is a lifelong process. A significant difference was found for the theme of Knowledge for a large size high school as compared to small and medium size high schools. Large high schools may focus more on obtaining, refining, and using knowledge than small or medium size high schools. Large high schools have more available resources to use and to teach students at a high level. This research study added the knowledge base on current mission statement studies, especially in high schools, where studies thus far have been limited. The study has specific applications that school administrators can use to improve their high school mission statements that are related directly to high student performance. 


\section{AUTHOR INFORMATION}

John Perfetto is an administrator at the Weslaco High School who works with teachers and staff to improve instruction, curriculum, organization, and decision making on the campus. He has worked on the campus for almost 23 years and has worked in almost every capacity that there is as an administrator on a high school campus. He received his Doctorate in Education Leadership in August of 2010. He continues to be a fervent believer that teachers in the classroom are the individuals who have greatest influence on student learning. He actively works with teachers and other administrators to maximize learning for all students. E-mail: jcperfetto@yahoo.com

Glenda Holland is professor and chair of educational leadership and counseling at Texas A\&M University Commerce where she serves as coordinator of the educational leadership doctoral program. She has also worked in P12 Texas schools. Her professional interests include recruitment and retention of educators as well as program assessment and improvement. E-mail: glenda.holland@tamuk.edu (Corresponding author)

Rebecca Davis is an associate professor and Executive Director of Research and Sponsored Programs at Texas A\&M University-Kingsville. She has worked in the adult education field in New Hampshire and Texas. She has a terminal degree from Texas A\&M University-College Station. Her professional interests include program administration, conference planning, emotional intelligence and the teaching/learning transaction. E-mail: rebecca.davis@tamuk.edu

La Vonne Fedynich is an Associate Professor and Coordinator of the Educational Administration program in the Department of Educational Leadership and Counseling. She came to Texas A\&M University-Kingsville in 2005. She holds advanced degrees in Education and Educational Leadership. Research interests are in the areas of graduate student success and multicultural education. E-mail: Lavonne.fedynich@tamuk.edu

\section{REFERENCES}

1. Abelman, R., \& Dalessandro, A. (2008). The institutional vision of community colleges. Community College Review, 35(4), 306-335.

2. Ayers, D. F. (2002). Mission priorities of community colleges in the southern United States. Community College Review, 30(3), 11-30.

3. Barnett, R. B., Glass, J. C., Snowdon, R. I., \& Stringer, K. S. (2002). Size, performance and effectiveness: Cost-constrained measures of best practice performance and secondary-school size. Education Economics, 10(3), 291-311.

4. Boerema, A. J. (2006). An analysis of private school mission statements. Peabody Journal of Education, 81(1), 182-183.

5. Bradley, S., \& Taylor, J. (1998). The effect of school size on exam performance in secondary schools. Oxford Bulletin of Economics and Statistics, 60(3), 291-324.

6. Carver, J. (2000). Managing your mission: Advise on where to begin. About Campus, 4(6), 19-23.

7. Cohen, J. (1988). Statistical power for analysis for the behavioral sciences (2nd ed.). Hillsdale, NJ: Lawrence Erlbaum Associates, Inc.

8. Davies, G. K. (1986). The importance of being general: Philosophy, politics, and institutional mission statements. In Morphew, C. C., \& Hartley, M. (2006). Mission statements: A thematic analysis of rhetoric across institutional type [Electronic version]. Journal of Higher Education, 77(3), 456-471.

9. Fairchild, H. H. (1984). School size, per-pupil expenditures, and school achievement. Los Angeles: University of California.

10. Glaser, B. G., \& Strauss, A. L. (1967). The discovery of grounded theory: Strategies for qualitative research. Chicago: Aldine.

11. Green, S. B., \& Salkind, N. J. (2005). Using SPSS for Windows and Macintosh: Analyzing and understanding data (Fourth Ed.). Upper River, NJ: Pearson Education, Inc.

12. Ireland, R. D., \& Hitt, M. A. (1992). Mission statement: Importance, challenge and recommendations for development. Business Horizons, 35(3), p. 34-42.

13. Levin, J. (2000, Fall). The revised institution: The community college mission at the end of the twentieth century. Community College Review, 28(2), p. 1-19. 
14. Morphew, C. C., \& Hartley, M. (2006). Mission statements: A thematic analysis of rhetoric across institutional type [Electronic version]. Journal of Higher Education, 77(3), 456-471.

15. Onwuegbuzie, A. J. (2003). Effect sizes in qualitative research: A prolegomenon. Quality \& Quantity: International Journal of Methodology. In Powel, H., Mihalas, S., Onwuegbuzie, A. J., Shannon, S. H., \& Daley, C. E. (2008). Mixed methods research in school psychology: A mixed methods investigation of trends in the literature. Psychology in the Schools, 45(4), 1-20.

16. Raynor, A. F. (2007). Save the last chance for me: Quality education in high schools for the young people who need it most. The High School Journal, 90(2), 51-58.

17. Tashakkori, A., \& Teddlie, C. (1998). Mixed methodology: Combining qualitative and quantitative approaches. Applied Social Research Methods Series, 46. Thousand Oaks, CA: Sage Publications.

18. United States Department of Education. (2008). Open high school application. 2008 No Child left BehindBlue Ribbon Schools Program Retrieved from http://www2.ed.gov/ programs/nclbbrs/2008/applications

19. Wang, J., Gibson, A. M., Soliz, F., \& Slate, J. R. (2007, March). Thematic differences in mission statements between four-year public institutions and two-year colleges. International Electronic Journal for Leadership In Learning, 11(1), 1-24. 